\section{Commentary: Zoom into the future with the virtual mock oral examination}

\author{
Leora B. Balsam, MD
}

The American Board of Thoracic Surgery (ABTS) certifying examination is an oral examination that evaluates clinical problem solving, surgical judgment, and behavior. Passing the examination is a necessary step in the ABTS board-certification process, with pass rates ranging from $72 \%$ to $84 \%$ over the last 5 years. ${ }^{1}$ The proportion of first-time passage on the examination is also a measure used by the American Council of Graduate Medical Education to assess cardiothoracic training programs, whereby poor performance may lead to loss of accreditation.

Many training programs have implemented mock oral examinations to simulate the ABTS certifying examination. There is considerable variability in the structure of these examinations, but the basic premise remains the same: a question bank, grading structure, examiners, and examinees are needed. Major barriers to implementation include access to suitable scenarios and examiners. ${ }^{2}$ Regional mock oral examinations are offered in some cities and geographies, which increases the pool of examiners and allows residents to be paired with examiners from other institutions. These collaborative mock oral examinations better simulate the experience of the ABTS certifying examination, where the candidate is examined by unfamiliar examiners.

In the field of surgery, some, but not all, studies have found a positive correlation between trainee performance on mock oral examinations and first-time passage of the

From the Division of Cardiac Surgery, UMass Memorial Medical Center, Worcester, Mass.

Disclosures: The author reported no conflicts of interest.

The Journal policy requires editors and reviewers to disclose conflicts of interest and to decline handling or reviewing manuscripts for which they may have a conflict of interest. The editors and reviewers of this article have no conflicts of interest.

Received for publication Aug 5, 2020; revisions received Aug 5, 2020; accepted for publication Aug 13, 2020; available ahead of print Sept 9, 2020.

Address for reprints: Leora B. Balsam, MD, Division of Cardiac Surgery, UMass Memorial Medical Center, University Campus, 55 Lake Ave North, Worcester, MA 01655 (E-mail: leora.balsam@umassmemorial.org).

JTCVS Open 2020;3:138-9

2666-2736

Copyright $(2020$ The Authors. Published by Elsevier Inc. on behalf of The American Association for Thoracic Surgery. This is an open access article under the CC BY-NCND license (http://creativecommons.org/licenses/by-nc-nd/4.0/).

https://doi.org/10.1016/j.xjon.2020.08.007

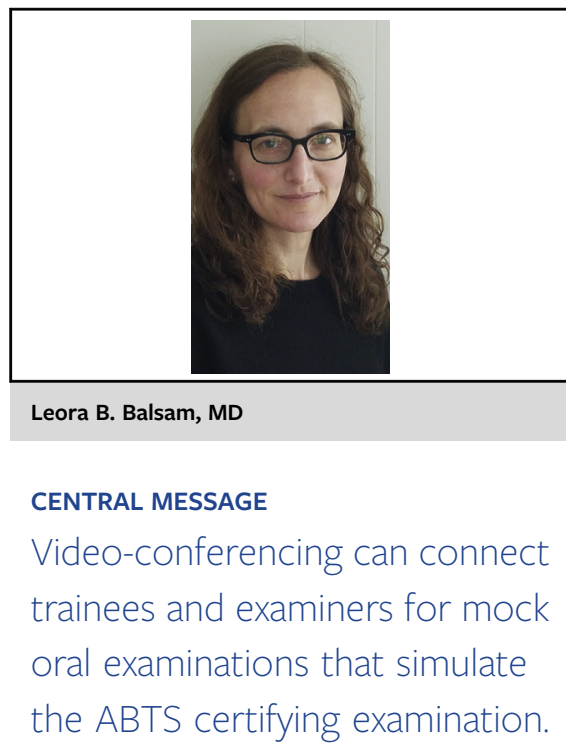

American Board of Surgery certifying examination..$^{3-5}$ When surveyed, most residents find the mock oral experience to be "useful," even if it doesn't directly translate into better performance on the certifying examination. In addition, program directors may use it as a measure for identifying areas of weakness in the individual trainee and the program as a whole.

In this issue of the Journal, Fiedler and colleagues ${ }^{6}$ describe the development of a multi-institutional mock oral board examination on a video-conferencing platform (Zoom). Residents and faculty from 6 cardiothoracic surgery training programs participated, with residents being examined by a pair of faculty members in a virtual thoracic room and a virtual cardiac room. In post-examination surveys, the feedback from both trainees and examiners was overwhelmingly positive.

Out of necessity, the coronavirus disease 2019 (COVID-19) pandemic has brought virtual meeting platforms to the forefront in our professional lives. With its potential to bring together examiners and examinees from different geographies in real-time, video-conferencing offers a reasonable simulation of the actual certifying examination. It is uncertain when and how the 2020 ABTS certifying examinations will be performed, as the need for social distancing and travel restrictions are significant barriers. We are at an interesting inflection point where the ABTS has the opportunity to reevaluate the examination structure and its value.

The study by Fiedler and colleagues ${ }^{6}$ is exploratory and does not attempt to show a relationship between the virtual mock oral examination and performance on the actual certifying examination. As a simulation, a notable 
weakness was that the examiners were not all ABTScertified (some were board-eligible); therefore, their ability to administer the examination, judge performance, and gauge the "usefulness" of the experience is uncertain. Finding qualified examiners is a common theme when discussing barriers to implementing mock oral boards. ${ }^{2}$ However, the virtual platform does create the opportunity to access a wider pool of faculty across different institutions and geographies, which may allow for a better simulated examination in the future.

The ABTS may take note of this pilot as it considers how to move forward with the certifying examination amidst our "new normal" in the COVID-19 era. Video-conferencing may in fact be a better strategy for the examination both during and postpandemic, allowing for greater flexibility in scheduling and significant cost reduction.

\section{References}

1. American Board of Thoracic Surgery website. Available at: https://www.abts.org/ ABTS/CertificationWebPages/Initial_Certification_Page.aspx. Accessed August 4, 2020.

2. Kimbrough MK, Thrush CR, Smeds MR, Cobos RJ, Harris TJ, Bentley FR. National landscape of general surgery mock oral examination practices: survey of residency program directions. J Surg Educ. 2018;75:54-60.

3. Fingeret AL, Arnell T, McNelis J, Statter M, Dresner L, Widmann W. Sequential participation in a multi-institutional mock oral examination is associated with improved American Board of Surgery certifying examination first-time pass rate. J Surg Educ. 2016;73:95-103.

4. Aboulian A, Schwartz S, Kaji AH, de Virgilio C. The public mock oral: a usefu tool for examinees and the audience in preparation for the American Board of Surgery certifying examination. J Surg Educ. 2010;67:33-6.

5. Higgins RM, Deal RA, Rinewalt D, Hollinger EF, Janssen I, Poirier J, et al. The utility of mock oral examinations in preparation for the American Board of Surgery certifying examination. Am J Surg. 2016;211:416-20.

6. Fiedler AG, Emerson D, Gillaspie E, Hermsen JL, Levack M, McCarthy DP, et al Multi-institutional collaborative mock oral (mICMO) examination for cardiothoracic surgery trainees: results from the pilot experience. J Thorac Cardiovasc Surg Open. 2020;3:128-35. 